\title{
Genome Size in Diploids, Allopolyploids, and Autopolyploids of Mediterranean Triticeae
}

\author{
T. Eilam, ${ }^{1}$ Y. Anikster, ${ }^{1}$ E. Millet, ${ }^{1}$ J. Manisterski, ${ }^{1}$ and M. Feldman ${ }^{2}$ \\ ${ }^{1}$ Institute for Cereal Crops Improvement, Tel Aviv University, 69978 Tel Aviv, Israel \\ ${ }^{2}$ Department of Plant Sciences, Weizmann Institute of Science, 76100 Rehovot, Israel
}

Correspondence should be addressed to M. Feldman, moshe.feldman@weizmann.ac.il

Received 12 January 2010; Accepted 29 April 2010

Academic Editor: Jaroslav Doležel

Copyright () 2010 T. Eilam et al. This is an open access article distributed under the Creative Commons Attribution License, which permits unrestricted use, distribution, and reproduction in any medium, provided the original work is properly cited.

\begin{abstract}
Nuclear DNA amount, determined by the flow cytometry method, in diploids, natural and synthetic allopolyploids, and natural and synthetic autopolyploids of the tribe Triticeae (Poaceae) is reviewed here and discussed. In contrast to the very small and nonsignificant variation in nuclear DNA amount that was found at the intraspecific level, the variation at the interspecific level is very large. Evidently changes in genome size are either the cause or the result of speciation. Typical autopolyploids had the expected additive DNA amount of their diploid parents, whereas natural and synthetic cytologically diploidized autopolyploids and natural and synthetic allopolyploids had significantly less DNA than the sum of their parents. Thus, genome downsizing, occurring during or immediately after the formation of these polyploids, provides the physical basis for their cytological diploidization, that is, diploid-like meiotic behavior. Possible mechanisms that are involved in genome downsizing and the biological significance of this phenomenon are discussed.
\end{abstract}

\section{Introduction}

The study of nuclear DNA amount (C-value in pg) in many plant groups during the last several decades not only yielded data on nuclear DNA amount in a large number of plants (see the Plant DNA C-values Database at Royal Botanic Gardens, Kew, available from http://data.kew.org/cvalues/), but has also contributed to a variety of related studies such as ploidy screening, detection of aneuploids, cell cycle kinetics, and reproductive pathways [1] and, through this, to several scientific disciplines including systematics, cytogenetics, and evolution [2]. The understanding that related species may differ in genome size and that these differences result primarily from changes in the amount of noncoding DNA [3] has motivated studies on the genetic and evolutionary significance of these differences, on the patterns of genome size changes in different plant groups, and on mechanisms underlying genome expansion or contraction.

The determination of nuclear DNA amount in many plant species has been performed with different methods, some of which are outdated and less accurate than flow cytometry [1-5]. Consequently, data obtained by different scientists using different methods for the same species were inconsistent. Therefore, as yet, there is no clear-cut knowledge as to the degree of variation in genome size neither at the intra-specific level nor for the occurrence and extent of genome downsizing in allopolyploids and autopolyploids.

One of the intriguing issues concerning evolutionary dynamics of plant genomes is the extent of intra-specific variation in genome size. Several previous studies have shown that there is a significant variation in genome size at the intra-specific level of several plant species, for example, Dasypyrum villosum [6], Arachis hypogaea [7], and Hordeum spontaneum [8]. However, these findings were questioned in several cases by reinvestigation with an improved technical approach [9].

Using the DNA C-values database, Leitch and Bennett [10] found that many polyploids from diverged groups of species showed a reduction in nuclear DNA amount relative to that of the respective diploids and that the mean DNA amount per basic genome (DNA amount divided by the level of ploidy) tends to decrease with increasing ploidy. They concluded that genome downsizing following polyploid 
formation is a widespread phenomenon. However, Leitch and Bennett [10] also noted that in most cases the precise parental genome donors of the studied polyploid species were unknown and, therefore, many comparisons between polyploids and their putative diploids were inappropriate. Despite the study of Leitch and Bennett [10], there is still conflicting evidence in different plant groups concerning the question whether the $\mathrm{C}$-value of a polyploid is less than the sum of the C-values of its diploid parents (e.g., [11-14]) and, therefore, this question deserves further consideration. Also, Leitch and Bennett [10] did not distinguish between allopolyploids and autopolyploids; the latter might contain the expected additive amount of the nuclear DNA of their diploid parents [15-17]. The data of the Plant DNA Cvalues Database at Royal Botanic Gardens, Kew (available from http://data.kew.org/cvalues/), show that while several autopolyploids contain the expected additive DNA amount others contain smaller amount of DNA than expected. Hence, the effect of autopolyploidization on genome size is not clear and has not been studied adequately.

Recently, using flow cytometry, Eilam et al. [18-20] studied these topics in species of the tribe Triticeae (Poaceae). The species of this tribe exhibit large differences in their genome size with nuclear DNA amount ranging from $4.0 \mathrm{pg}$ per 1C nucleus in Elymus libanotica to $8.3 \mathrm{pg}$ in Secale cereale $[21,22]$. Since these differences may reflect genome complexity that bears genetic and evolutionary meaning, it was of interest to determine the ranges of intraspecific variation in genome size in these species and to see to what extent allopolyploidy and autopolyploidy affect genome size. This paper reviews recent data on genome size in diploid, allopolyploid, typical autopolyploid, and cytologically diploidized autopolyploid taxa of Mediterranean Triticeae [18-20].

The tribe Triticeae of the family Poaceae includes 16 genera comprising several hundreds of species that grow mainly in the temperate-arctic and Mediterranean-central Asiatic regions of the northern hemisphere. Several evolutionary trends have been recognized in this tribe: the primitive genera contain perennial species that have spikelets in groups at each rachis internode and grow mainly in the temperate-arctic region while the more advanced genera contain annual species that have solitary spikelets at each rachis internode and grow mainly in the Mediteranneancentral Asiatic regions [23]. Another significant evolutionary trend in this tribe is the prevalence of polyploidy (allopolyploidy and autopolyploidy) in most of the genera: about $31 \%$ of the species are diploids and $69 \%$ are polyploids in this tribe. The evolutionary success of allopolyploids and autopolyploids stems from a different genetic system. Allopolyploids, derived from inter-specific and intergeneric hybridization followed by chromosome doubling, have two or more diverged (homoeologous) genomes. These genomes usually undergo further divergence resulting in cytological diploidization and consequently, diploid-like meiotic behavior that leads to full fertility and disomic inheritance [2426]. Such a genetic system, reinforced by predominant selfpollination, may result in true breeding and permanent maintenance of favorable intergenomic genetic interactions between homoeoalleles [26]. Autopolyploids, on the other hand, originated mostly from intra-specific hybridization followed by chromosome doubling, have multiplicity of homologous genomes. Thus, their chromosomes may form multivalents during meiosis leading to a multisomic inheritance. One advantage of autopolyploidy is the capability to maintain different degrees of intralocus heterozygosity, or more rarely, to reach homozygosity with multiple dosage of a given allele. Thus, in spite of the fact that multivalent pairing is often associated with some degree of sterility, selection in some autopolyploids will favor multivalent formation, and therefore will act against genomic changes that may lead to cytological and genetic diploidization. Nevertheless, in addition to these "typical autopolyploids", there are many autopolyploids that underwent cytological and genetic diploidization and consequently form only or mostly bivalents at meiosis. These "cytologically diploidized autopolyploids" [20] may have multisomic inheritance if the bivalents are formed at random between the four homologues, or may have disomic inheritance if the bivalents are formed always between the same partners as a result of preferential pairing.

The taxonomy of the Triticeae in this paper follows that of Clayton and Renvoize [27] and that of the AegilopsTriticum species follows that of Eig [28] and van Slageren [29]. Genome designation of the Triticeae species is after Wang et al. [30] and that of Aegilops and Triticum is after Kimber and Tsunewaki [31].

\section{Genome Size at the Intraspecific and Interspecific Levels}

The nuclear 1C DNA amount in diploid and allopolyploid Triticeae species and in diploid and autopolyploid Triticeae cytotypes exhibits very small variation between plants of the same line just as the variation between lines (Table 1; see also [18, Tables 1 and 2], [19, Tables 1 and 2 ] and [20, Tables 1 and 3]). The analysis of variance revealed that most variation $(>92 \%)$ was due to species or cytotypes whereas between plants and between lines variation contributed together to the total variation only a small fraction of this value. This intra-specific or intracytotype stability in genome size was found among lines that were collected from different parts of the species' geographical distributions as well as from different habitats. Different morphs of each species such as small and large types of wild barley that were collected from different localities did not differ in their nuclear DNA amount. Also there were no significant differences in nuclear DNA amount of lines that were collected from different habitats (e.g., dry versus humid, hot versus cold, and peripheral versus central). No significant difference in DNA amount was found between lines of wild and domesticated diploid and tetraploid wheat and between wild (H. spontaneum) and domesticated (H. vulgare) barley. The intra-specific and intracytotype stability in nuclear DNA amount indicates that there were very little changes, if any, in DNA amount during the life history of the diploids, allopolyploids, and autopolyploids. 
TABLE 1: Analysis of variance and variance components estimates of DNA content in different lines of 22 diploid Triticeae species (a), in different lines of 24 allopolyploid species of Aegilops and Triticum (b), and in different lines of diploid and autotetraploid cytotypes of Elymus and Hordeum (c) analyzed in a random effect model.

(a) Diploid species.

\begin{tabular}{|c|c|c|c|c|c|c|}
\hline Source of variation & df & $\begin{array}{l}\text { Sum of } \\
\text { squares }\end{array}$ & $\begin{array}{l}\text { Mean } \\
\text { square }\end{array}$ & $\mathrm{F}$ & $\begin{array}{l}\text { Variance } \\
\text { compo- } \\
\text { nents }\end{array}$ & $\begin{array}{l}\text { Percent of } \\
\text { total } \\
\text { variance }\end{array}$ \\
\hline Species & 22 & 288.056 & 13.0935 & $1049.204^{*}$ & 0.878816 & 98.814 \\
\hline Lines (Species) & 249 & 3.123 & 0.01254 & $1.8292^{*}$ & 0.003693 & 0.415 \\
\hline Plants (Lines, Species) & 166 & 1.138 & 0.00686 & - & 0.006857 & 0.771 \\
\hline Total & & & & & 0.889366 & 100.000 \\
\hline
\end{tabular}

(b) Allotetraploid and allohexaploid species.

\begin{tabular}{|c|c|c|c|c|c|c|c|}
\hline Group & $\begin{array}{l}\text { Source of } \\
\text { variation }\end{array}$ & $\mathrm{df}$ & $\begin{array}{l}\text { Sum of } \\
\text { squares }\end{array}$ & $\begin{array}{l}\text { Mean } \\
\text { square }\end{array}$ & $\mathrm{F}$ & $\begin{array}{l}\text { Variance } \\
\text { compo- } \\
\text { nents }\end{array}$ & $\begin{array}{l}\text { Percent of } \\
\text { total variance }\end{array}$ \\
\hline \multirow{4}{*}{ Tetraploids } & Species & 18 & 150.087 & 8.3382 & $80.444^{* *}$ & 1.05737 & 90.97 \\
\hline & Lines (Species) & 64 & 6.650 & 0.1039 & 0.979 n.s. & -0.00107 & -0.09 \\
\hline & $\begin{array}{l}\text { Plants (Lines, } \\
\text { Species) }\end{array}$ & 95 & 10.080 & 0.1061 & - & 0.10610 & 9.13 \\
\hline & Total & & & & & 1.16246 & 100.00 \\
\hline \multirow{4}{*}{ Hexaploids } & Species & 6 & 4.232 & 0.7053 & $5.168^{*}$ & 0.14267 & 61.73 \\
\hline & Lines (Species) & 14 & 1.720 & 0.1228 & $3.664^{*}$ & 0.05492 & 23.76 \\
\hline & $\begin{array}{l}\text { Plants (Lines, } \\
\text { Species) }\end{array}$ & 16 & 0.536 & 0.0335 & - & 0.03352 & 14.51 \\
\hline & Total & & & & & 0.23111 & 100.00 \\
\hline
\end{tabular}

(c) Diploid and autotetraploid cytotypes.

\begin{tabular}{|c|c|c|c|c|c|c|c|}
\hline Group & $\begin{array}{l}\text { Source of } \\
\text { variation }\end{array}$ & df & $\begin{array}{l}\text { Sum of } \\
\text { squares }\end{array}$ & $\begin{array}{l}\text { Mean } \\
\text { square }\end{array}$ & $\mathrm{F}$ & $\begin{array}{l}\text { Variance } \\
\text { components }\end{array}$ & $\begin{array}{l}\text { Percent } \\
\text { of total } \\
\text { variance }\end{array}$ \\
\hline \multirow{5}{*}{ Diploids } & Cytotypes & 3 & 5.725 & 1.9082 & $94.649^{*}$ & 0.54589 & 97.03 \\
\hline & $\begin{array}{l}\text { Lines } \\
\text { (Cytotypes) }\end{array}$ & 11 & 0.261 & 0.0238 & $7.895^{*}$ & 0.01373 & 2.44 \\
\hline & $\begin{array}{l}\text { Plants (Lines, } \\
\text { Cytotypes) }\end{array}$ & 24 & 0.078 & 0.0032 & 1.641 & 0.00113 & 0.20 \\
\hline & Residual & & & & & 0.01850 & 0.33 \\
\hline & Total & & & & & 0.56261 & 100.00 \\
\hline \multirow{5}{*}{ Tetraploids } & Cytotypes & 4 & 35.870 & 8.9676 & $101.618^{*}$ & 0.06829 & 56.63 \\
\hline & $\begin{array}{l}\text { Lines } \\
\text { (Cytotypes) }\end{array}$ & 30 & 2.893 & 0.0964 & $8.671^{*}$ & 0.03500 & 27.49 \\
\hline & $\begin{array}{l}\text { Plants (Lines, } \\
\text { Cytotypes) }\end{array}$ & 37 & 0.394 & 0.0106 & 0.576 & 0.00009 & 0.07 \\
\hline & Residual & & & & & 0.02396 & 18.82 \\
\hline & Total & & & & & 0.12735 & 100.00 \\
\hline
\end{tabular}

${ }^{*} P \leq .01 ;{ }^{* *} P \leq .001$.

The great stability observed by Eilam et al. [18-20] in nuclear DNA amount at the intra-specific level of every studied Triticeae species is in accord with a large number of reports indicating lack of significant variation in genome size at the intra-specific level of other plant groups $[1,9,16,32$ 41]. These studies could not confirm previous observations (e.g., [6-8]) of intra-specific variation in genome size that were reported in several species. Hence, the data of Eilam et al. [18-20] support the notion that intra-specific variation in genome size is relatively small and non-significant $[9,42$, 43].

In contrast to the stability of genome size at the intraspecific level, there is a large and significant variation in this trait at the inter-specific and the intergeneric levels 
of the studied Triticeae species (Table 1; see also [1820]). No evidence was found in these studies indicating that self-pollinating species (most of the species) have considerably different nuclear DNA amounts than the crosspollinating species. Similarly, the values of DNA amounts of the perennial species fell within the range of values of the annual species (only Secale montanum has larger genome than its annual relatives). This is in accord with the data of Albach and Greilhuber [44] in Veronica species and Jakob et al. [16] in Hordeum species and in contrast to previous reports $[45,46]$ claiming that annual, self-pollinating species have smaller genomes than perennial, cross-pollinating ones. Diploid species that grow in the southern part of the distribution area of the genus Aegilops, that is, in hotter and drier habitats (Aegilops bicornis, Ae. searsii, Ae. Longissima, and Ae. sharonensis), have significantly more DNA than species that grow in other parts of the distribution of Aegilops.

The genome-size stability at the intra-specific level of the Triticeae species studied here is striking in view of the fact that retrotransposons comprise a significant fraction of the genomes of many Triticeae species [47-49] and, as such, these genomes have a considerable potential to undergo rapid changes in nuclear DNA amount.

As found for the grass family in general [50], in the Triticeae too, there is no clear trend of genome-size evolution on the inter-specific level; in some species genome was increased while in others it was decreased. Increase in genome size can be brought about by the activation of transposons, especially retrotransposons [51-54], whereas decrease in DNA amount can result from a variety of recombinational mechanisms such as unequal homologous recombination between homologous chromosomes, sister chromatids, or intrachromatid; the latter can take place between long terminal repeats (LTRs) of retrotransposons [53, 55-57]. Decrease in DNA may also result from illegitimate recombination between chromosomes, sister chromatids, or intrachromatid $[53,57]$. The relative extent of these two counteracting mechanisms (retroelement proliferation and LTR recombination) determines the direction of genome-size change. The LTRs of a single retrotransposon diverge from one another with time, thus limiting the possibility of intrachromatid recombination. Consequently, old retrotransposons can only increase DNA amount by activation and transposition rather than decrease it by illegitimate intrachromatid recombination.

The inter-specific differences in genome size reflect mostly variation in the noncoding DNA since grass genomes contain a similar number of genes [58] and differences in genome size are mainly related to differences in transposable elements content $[3,59,60]$. The contrast between the low variation at the intra-specific level and the high variation at the inter-specific one (Table 1) may suggest that the inter-specific changes occurred during speciation. In other words, speciation within many Triticeae genera was either accompanied by or even resulted from a considerable change in nuclear DNA amount. Such a change could have been induced by environmental stress such as sudden heat, frost, and drought $[61,62]$, or genetic stress such as inter-specific hybridization [63].

\section{Genome Downsizing in Allopolyploids}

The wheat group (the genera Aegilops and Triticum) is most suitable for studying genome size in allopolyploids. It contains many allotetraploid and allohexaploid species that, because of their economic importance, have been subjected to an intensive cytogenetic study that has provided considerable information on the origin of their genomes and on the genomic relationships among them [64]. The amount of nuclear DNA was recently estimated in the diploid species of this group [18] and determination of nuclear DNA amount in the allopolyploids facilitated comparisons between the allopolyploids and their progenitors $[19,20]$. Moreover, it is rather easy to produce synthetic allopolyploids in this group and many such newly formed allopolyploids were recently synthesized [65]. In such material, comparisons were made not only between synthetic allopolyploids and their parental plants but also between synthetic and natural allopolyploids having the same genomic combination.

The nuclear 1C DNA amount in the allopolyploids of the wheat group was determined using flow cytometry [19]. The expected amount of nuclear DNA in each of the allotetraploid species was calculated from the sum of the DNA amount in their two parental diploid species and that in allohexaploid species from the sum of the DNA amount in the respective tetraploid and diploid parental species. The amount of DNA in most allopolyploid species was significantly smaller than the expected value ([19, Table 1] and Figure 1). The data of Eilam et al. [19] contradict several previous studies $[12,66-70]$ which measured DNA amount by staining the nuclei with the DNA-specific Feulgen stain followed by quantifying the absorption of the visible monochromatic light. They showed that the nuclear DNA amount in Aegilops and Triticum allopolyploids is the sum of the DNA amount of their parental species. The discrepancy between these results and those of Eilam et al. [19] may be explained by the method of estimation of DNA amount. Eilam et al. [19] estimated nuclear DNA amount by flow cytometry that is a more accurate and precise method [1], in a relatively large number of plants in each species and in a large number of nuclei in every plant, each plant in several replicates. The accuracy of the method used by Eilam et al. [19] is evident from the non-significant differences that were obtained between replicates. Moreover, the results of Eilam et al. [19] are in accord with those of Pai et al. [71] and Upadhya and Swaminathan [72] who found that DNA content in hexaploid wheat is less than expected from the amount of its parental species. Similarly, Boyko et al. [73, 74] found a decrease in DNA amount of octoploid and hexaploid triticale (Triticosecale), respectively, as compared to the combined wheat and rye (Secale cereale) values. All these data are in accord with recent findings that allopolyploidization leads to instantaneous elimination of DNA sequences in the wheat group [24, 65, 75-81] and in triticale [82-84].

The results of Eilam et al. [19] show that the allotetraploid species of Triticum, T. turgidum (genome BBAA), had larger amount of DNA than the expected value which was calculated on the assumption that Ae. speltoides is the donor of the B genome and T. urartu is the donor of 


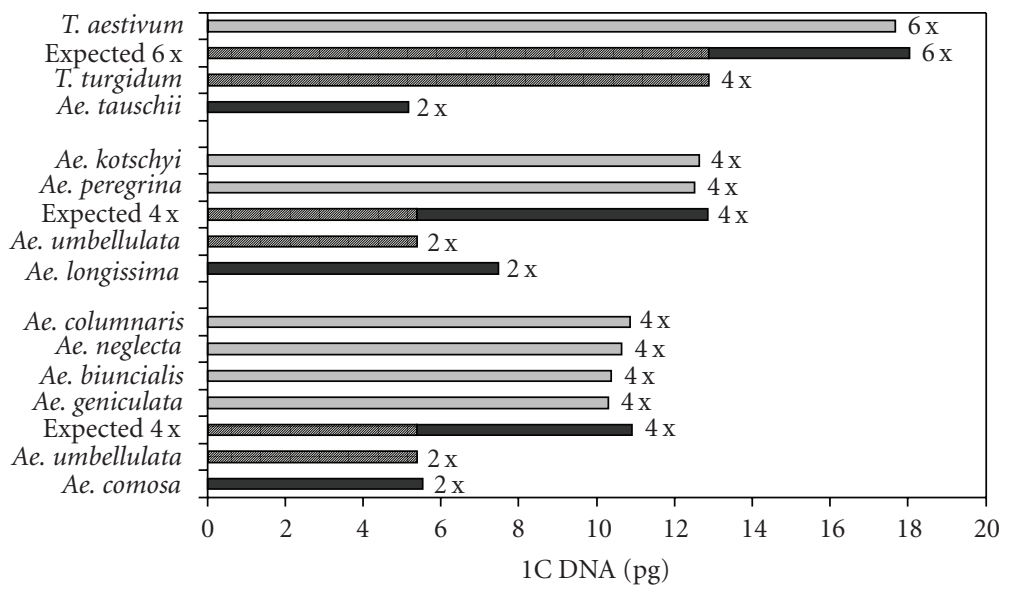

FIGURE 1: Expected (black-stripped bars) and observed (gray-solid bars) nuclear 1C DNA amount in natural Aegilops allotetraploids ( $2 n=$ $4 x=28)$ having the UM or US genomes and Triticum allohexaploid $(2 n=6 x=42)$ having the BAD genome (data from [19]). Nuclear 1C DNA amount of the putative parental species is also presented. The differences between the expected and observed were significant $(t$-test; $P \leq .05)$ except those in Ae. neglecta and Ae. columnaris (in these two species a very small number of lines were analyzed).

the A genome. The deviation from the expected amount is very large and significant. Similar results were obtained by Furuta et al. [85] who found that the DNA content of Ae. speltoides is only about $87 \%$ of that of the $\mathrm{B}$ genome of hexaploid wheat and therefore concluded that Ae. speltoides is not the donor of the $\mathrm{B}$ genome. Hence, the $\mathrm{B}$ genome was either derived from a species containing more than $7.5 \mathrm{pg}$ DNA or, if it is derived from Ae. speltoides, its DNA amount was increased in the tetraploid wheat. If so, the $\mathrm{B}$ genome is unique in undergoing increase, as all other genomes of Aegilops and Triticum allopolyploids underwent downsizing, including the synthetic allopolyploids containing the $\mathrm{S}$ genome of Ae. speltoides (Figures 1 and 2 and [19]). The decrease in synthetic allpolyploids containing the $S$ genome is in accord with recent reports $[79,81]$ describing elimination of repetitive sequences from genome $S$ of $A e$. speltoides in newly formed allopolyploids.

The nuclear DNA amount of the newly formed allopolyploids and of their parental plants is presented in Figure 2. Eight out of ten synthetic allopolyploids contain significantly less DNA than the expected additive sum of DNA amounts of their two parental plants. The decrease in DNA amount is already evident in the first generations following chromosome doubling and remains fairly similar in subsequent generations. Comparison of nuclear DNA amount in synthetic and natural allopolyploids having the same genomic combination showed non-significant differences between them (Figure 3). These results are in accord with those of Ozkan et al. [86] who found in six newly synthesized wheat allohexaploids that they have a genome size significantly smaller than the expected additive value of their parental plants. Decrease in genome size occurred already in the first generation of the allopolyploids, indicating that the change was a rapid event [86]. This corresponds to the data of Ozkan et al. [65], Shaked et al. [78], and Ma and Gustafson [82] that elimination of DNA sequences occurs in the $\mathbf{F}_{1}$ hybrid and in the first generation(s) of the newly formed allopolyploids. The low variation in nuclear DNA amount at the intra-specific level (Table 1) suggests that the changes in genome size occurred soon after the formation of the allopolyploids and no further significant changes occur during the life history of the allopolyploids. The similarity in DNA values of natural and synthetic allopolyploids having the same genomic combinations (Figure 3) also shows that changes in DNA amount were reproducible and occurred immediately after the formation of the allopolyploids. An interesting question is, therefore, what stabilizes genome size in these allopolyploid species that contain large amount of transposable elements [47] that may, as a response to external or internal stimulation, increase or decrease nuclear DNA amount.

There is evidence indicating that the decrease in DNA amount in allopolyploids was not equal in the different constituent genomes and one genome underwent more drastic downsizing than the other(s). Extracted tetraploid wheat, having the $\mathrm{B}$ and $\mathrm{A}$ genomes of the allohexaploid wheat $T$. aestivum [87, 88], contains similar amount of nuclear DNA as the natural BBAA allotetraploid T. turgidum (Figure 4). Also Furuta et al. [70], Nishikawa and Furuta [89], and Nishikawa et al. [90] found that DNA content of BBAA genome component extracted from three cultivars of $T$. aestivum is equal to that of T. turgidum, indicating that DNA amount of the $\mathrm{B}$ and $\mathrm{A}$ genomes of T. aestivum did not change at the hexaploid level during 10,000 years of history of this wheat. It can be deduced, therefore, that the reduction in DNA amount in natural and synthetic allohexaploid wheat found by Eilam et al. [19] was mainly in the D genome. Consequently, the amount of nuclear DNA in the $\mathrm{D}$ genome of $T$. aestivum is $4.96 \mathrm{pg}$ ( $17.67 \mathrm{pg}$ in $T$. aestivum subsp. aestivum minus $12.91 \mathrm{pg}$ in the extracted tetraploid), that is, $11 \%$ smaller than that of Ae. tauschii, the diploid donor of the D genome to T. aestivum. Similarly, 


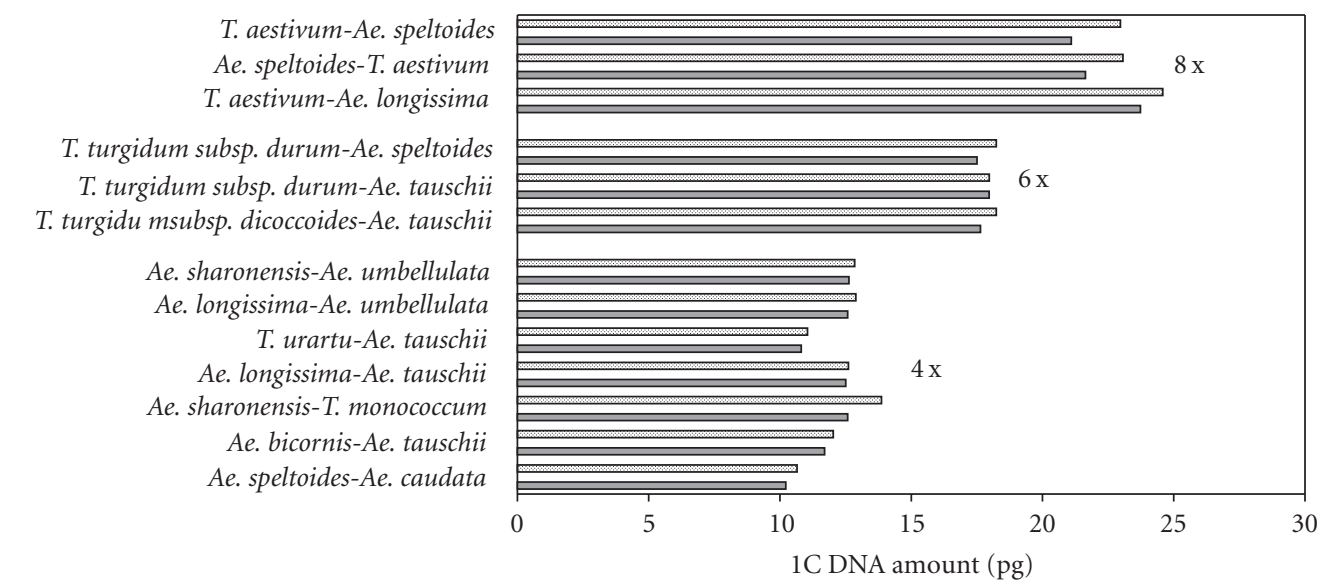

Figure 2: Nuclear 1C DNA amount in 4x, 6x, and 8x synthetic allopolyploids of Aegilops and Triticum (gray-solid bars) and DNA values expected from their parental plants' value (black-dotted bars) (data from [19]). The differences between expected and observed were significant ( $t$ test; $P \leq .05$ ) in all synthetic allopolyploids.

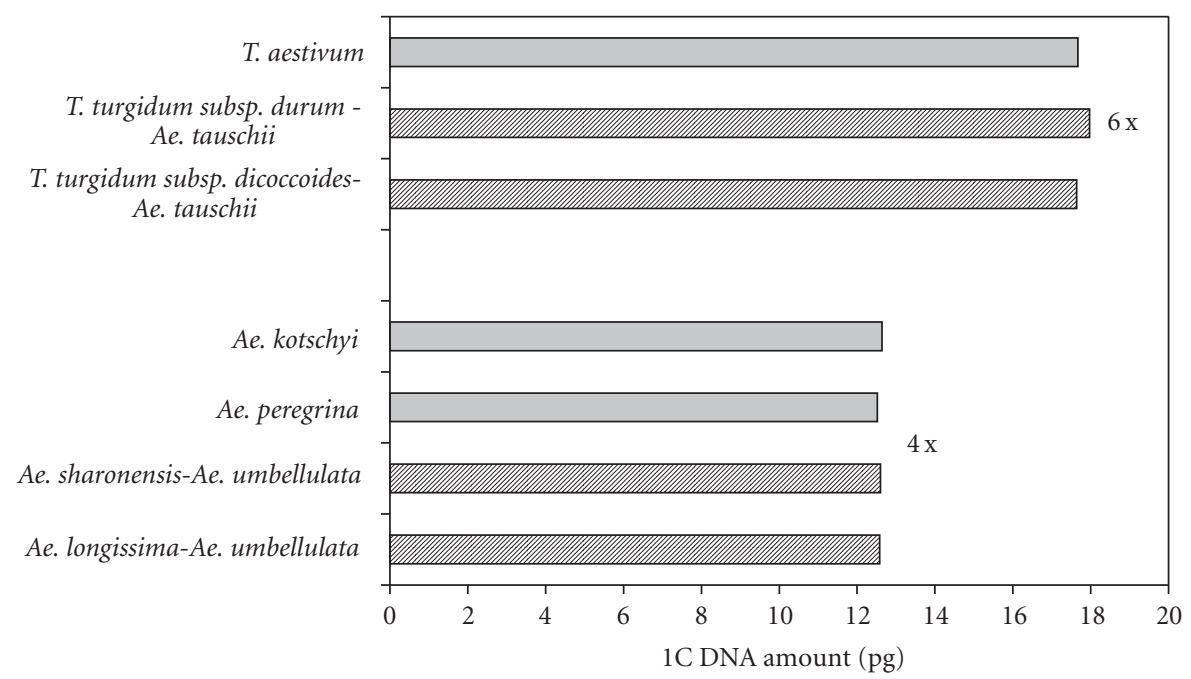

FIGURE 3: Nuclear 1C DNA amount in natural (gray-solid bars) and synthetic (black-reticulated bars) allopolyploids having similar genomic combinations (data from reference [19]). The differences between natural and synthetic are not significant $(t$-test; $P \leq .05)$.

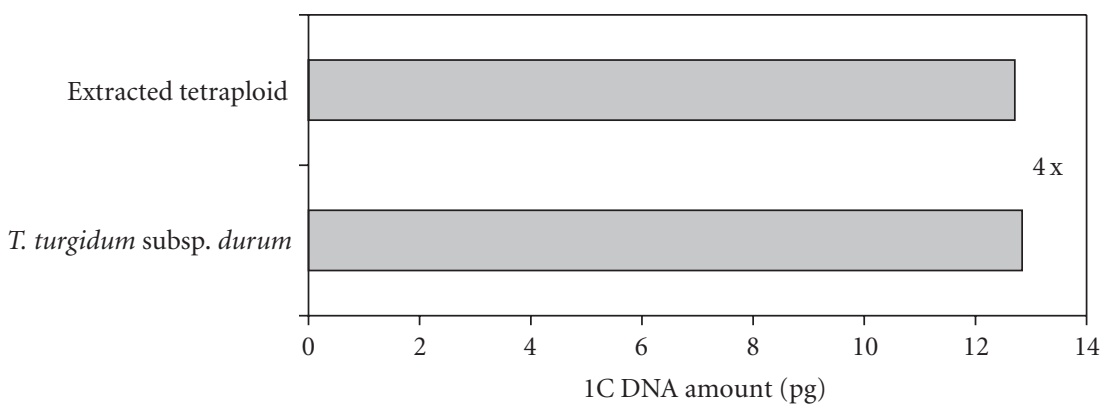

FIgURE 4: Nuclear 1C DNA amount in extracted tetraploid wheat $(2 n=4 x=28)$ having the B and A genomes of hexaploid wheat T. aestivum, and in tetraploid T. turgidum subsp. durum $(2 n=4 x=28$; genome BBAA) (data from [19]). No significant difference exists between the 1C DNA amounts of the two taxa. 
Furuta et al. [70] found that the D genome of the newly synthesized T. aestivum contains 4.39 pg DNA, $14.4 \%$ less than in Ae. tauschii. It is assumed that the $\mathrm{B}$ and $\mathrm{A}$ genomes underwent genome downsizing already at the tetraploid level and, therefore, did not change further at the hexaploid level. Likewise, Ma and Gustafson [83] described a differential decrease in DNA amount in the constituent genomes of a newly synthesized allopolyploid. They found in octoploid triticale a greater loss of DNA sequences from the rye genome than from the wheat ones.

The results described above are in accord with those of Leitch and Bennett [10] who found that genome downsizing characterizes wide groups of allopolyploids. Recent studies, for example, Vaio et al. [91] in allotetraploid Paspalum species, Johnston et al. [92] in Brassicaceae allopolyploid species, Vogel et al. [15] in Triticeae allopolyploid perennial species, and Pires et al. [13] in allotetraploid, Tragopogon miscellus, also show that genome downsizing in allopolyploids is a very prevalent phenomenon. Thus, genome downsizing, being a general response to allopolyploid formation, may represent an overall trend in allopolyploid evolution across the angiosperms [10].

\section{Genome Size in Autopolyploids}

Two types of autopolyploids are recognized in the Triticeae: "typical" and "cytologically diploidized" autopolyploids. Typical autopolyploids, represented by the tetraploid cytotype of Hordeum bulbosum L., are characterized by multivalent pairing at meiosis, four to five multivalents per meiocyte [93-95], and, consequently, multisomic inheritance. The formation of multivalents during meiosis is often associated with partial sterility. Thus, typical autopolyploids are prevalent among perennial species having the capacity for vegetative propagation in addition to the sexual one. Cytologically diploidized autopolyploids, represented by the tetraploid cytotype of Elymus elongatus (Host) Runemark [=Agropyron elongatum (Host) P. Beauv.], exhibit exclusive or almost exclusive bivalent pairing at meiosis in spite of the fact that originally they contained two or more homologous genomes [96-98]. The cytologically diploidized autopolyploids, being more fertile than the typical ones, are prevalent among annual species. The genus Hordeum contains several species that include tetraploid cytotypes exhibiting exclusive bivalent pairing at meiosis [99]. These cytotypes are either cytologically diploidized autopolyploids or segmental allopolyploids [16, 100, 101]. Many of these species are annuals lacking vegetative reproduction.

The nuclear DNA amount in diploid and tetraploid cytotypes of Hordeum bulbosum was determined [20]. It was found that this typical autopolyploid contains the expected additive DNA amount (see [20, Table 1]). Similarly, Vogel et al. [15] and Jakob et al. [16] found that the nuclear DNA amount of this autotetraploid cytotype does not deviate significantly from the expected additive value of its parental diploid cytotype. Likewise, the typical autotetraploid cytotype of Dactylis glomerata and autopolyploids of the genus Festuca (all exhibit multivalent pairing) contained the expected additive DNA content of their parental species [102]. Also tetraploid cytotypes of Allium species [103], newly induced autotetraploid Brassica plants [104], and an induced autotetraploid line of Festuca pratensis [105] showed no significant difference between the expected additive amount and observed DNA content. Similarly, Ozkan et al. [17], studying genome size in two newly formed autotetraploid accessions of Arabidopsis thaliana, found that they contained the expected additive amount of nuclear DNA. From the above it can be concluded that typical autopolyploids have the expected additive nuclear DNA amount of their parental diploids. The fact that no genome downsizing has occurred in these taxa indicates that the homology between the homologous chromosomes of the constituent genomes is maintained, thus facilitating pairing between all homologous chromosomes and consequently formation of multivalents at meiosis.

In contrast to the additive value of genome size in typical autopolyploids, nuclear DNA amount in cytologically diploidized autotetraploids exhibits considerable genome downsizing. The nuclear DNA amount was determined in diploid and autotetraploid cytotypes of E. elongatus and in diploid and autotetraploid cytotypes of several Hordeum species [20]. Evidently, the tetraploid cytotypes contained much less DNA than the expected additive amount of the diploid cytotypes (Figures 5 and 6). The nuclear DNA amount in a newly synthesized autotetraploid line of E. elongatus was found to be significantly smaller than the expected additive value of the diploid parental plant (Figure 5). Comparison of the nuclear DNA amount in the synthetic and the natural autotetraploid cytotypes of E. elongatus showed small and non-significant difference between them (Figure 5), thus indicating that genome downsizing in this autopolyploid was reproducible and occurred immediately after polyploidization and there were no further changes in genome size during its life history.

The cytologically diploidized autotetraploid H. murinum subsp. murinum and the segmental allotetraploid $H$. murinum subsp. leporinum also had significantly less nuclear DNA than the expected value (Figure 6). Similar results were obtained by Raina et al. [106] who described decrease in DNA amount in newly synthesized autotetraploid Phlox: DNA amount was decreased by $16.7 \%$ in $\mathrm{C}_{0}$ and by $25 \%$ in $\mathrm{C}_{2}$ generation. The loss was the outcome of equal reduction in all of the chromosomes. Rapid DNA loss in the first and second generations was associated with increased seed set and also helped in the establishment and stabilization of the autotetraploid [106].

The cytologically diploidized autotetraploids studied here form exclusively bivalents at meiosis [97-99, 107, 108]. The shift from potentially multivalent pairing towards bivalent type of pairing in these autopolyploids presumably was brought about by instantaneous elimination of DNA sequences that are involved in homology recognition and initiation of meiotic pairing from two out of the four homologous chromosomes in each set of four, several sequences from one pair and other sequences from the second pair. Indeed, Dvorak [109] noticed that the two genomes of the tetraploid cytotype of E. elongatus appeared 


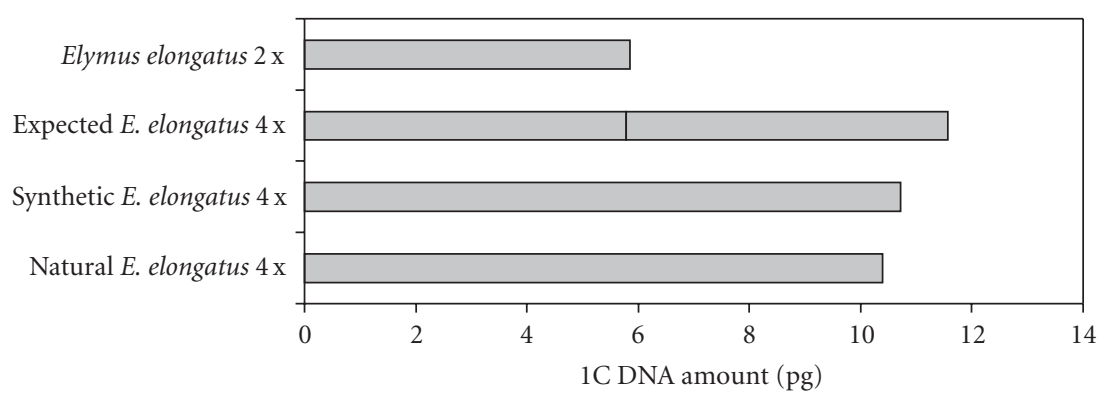

FIGURE 5: Expected and observed nuclear 1C DNA amount in natural and synthetic autotetraploid Elymus elongatus and in the diploid parental plant of the synthetic autotetraploid (data from [20]).

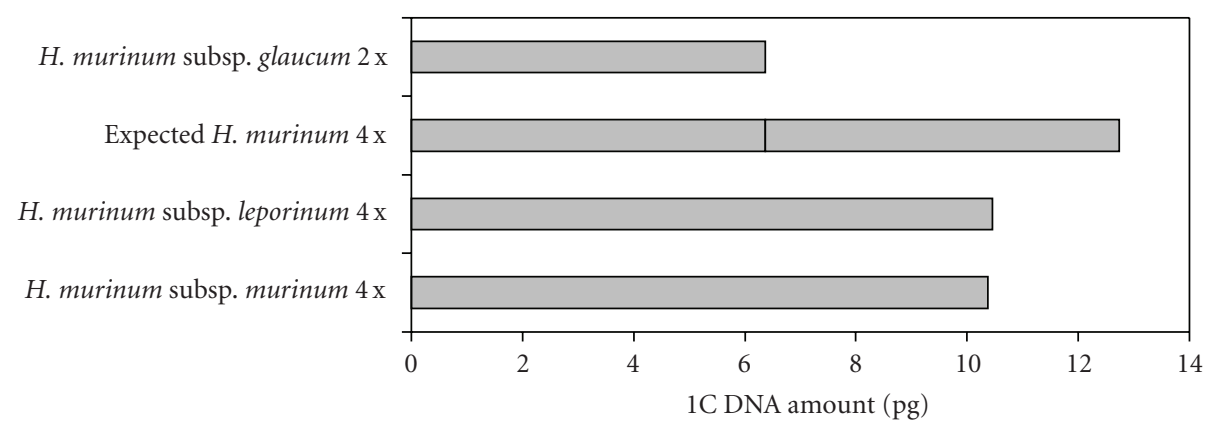

FIGURE 6: Expected and observed nuclear 1C DNA amount in diploid and natural autotetraploid subspecies of Hordeum murinum (data from [20]).

to be a modified version of the diploid genome. Since the two genomes are slightly diverged, pairing between fully homologous chromosomes, that is, intra-genomic pairing, leads to bivalents at meiosis and disomic inheritance [109].

The data presented here indicate that the bivalent pattern of pairing exhibited by the tetraploid cytotypes of E. elongatus, H.murinum subsp. Murinum, and H. murinum subsp. leporinum may have resulted from instantaneous elimination of DNA sequences-several sequences from one of the genomes and others from the second genomethus augmenting the divergence between the homologous chromosomes of the different genomes. A gene system, determining diploid-like meiotic behavior, may be superimposed on sequence elimination, taking advantage of the divergence between the homoeologues of the different genomes, and, consequently, allowing strict pairing between the same partners with the resultant disomic inheritance. Fixed heterozygosity caused by disomic inheritance was seen in the segmental allopolyploid $H$. murinum subsp. leporinum [110-113] and in the cytologically diploidized autotetraploid H. murinum subsp. murinum $[114,115]$. Thus, this group of autopolyploids benefit from full fertility and permanent fixing of heterozygosity between alleles of the partly diverged genomes.

In summation, genome downsizing in autopolyploids might bring about their cytological diploidization, facilitating their rapid and successful establishment in nature, increasing their competition with the parental species, and improving their adaptability to new environments. The decrease in DNA content occurs immediately after autopolyploidization with no further changes in DNA amount during the life of the autopolyploids or the segmental allopolyploids.

The cytologically diploidized autotetraploid H. marinum subsp. gussoneanum represents another type of autopolyploids, that is, cytologically diploidized autopolyploids with no reduction in nuclear DNA amount [20]. The nuclear DNA amount of this autotetraploid cytotype found by Vogel et al. [15], Jakob et al. [16], and Eilam et al. [20] did not deviate significantly from its expected additive value. Since no significant changes in DNA amount were found in this tetraploid cytotype, it is assumed that the four partners in each chromosome group have remained homologous. However, this taxon forms exclusively bivalents at meiosis [99]. The bivalents may be formed at random between the four partner homologous chromosomes, that is, different partners in different cells, and, consequently, multisomic inheritance prevails. Alternatively, the bivalents are formed always between the same partner homologues with the resultant disomic inheritance. While multisomic inheritance is characteristic of autohexaploid Phleum pratense $(2 n=$ $6 x=42$ ) which forms 21 bivalents at meiosis but displays hexasomic inheritance $[116,117]$, and of Lotus corniculatus $(2 n=4 x=24)$, which forms 12 bivalents at meiosis and has tetrasomic inheritance [118], disomic inheritance, 
inferred from isozyme studies, is the mode of inheritance in H. marinum subsp. gussoneanum $[114,119]$.

\section{Biological Significance of Genome Downsizing in Allopolyploids and Cytologically Diploidized Autopolyploids}

Feldman et al. [24], Ozkan et al. [65, 77], Levy and Feldman $[120,121]$, and Feldman and Levy $[25,26]$ suggested that rapid and nonrandom elimination of low-copy, noncoding DNA sequences from one of the two homoeologous pairs in tetraploids and from two homoeologous pairs in hexaploids further augments the differentiation of homoeologous chromosomes at the polyploid level and leads to cytological diploidization. Such elimination, which presumably also involved sequences having a role in homology recognition and initiation of meiotic pairing, provides the physical basis for the diploid-like meiotic behavior of allopolyploid Aegilops and Triticum species. As was found by Ozkan and Feldman [122], the extent of DNA elimination in newly formed allopolyploids was positively correlated with the frequency of bivalent pairing and with seed fertility. Diploidlike meiotic behavior sustains disomic inheritance, which, in turn, maintains favorable intergenomic combinations and permanent heterosis between homoeoalleles. Thus, cytological diploidization might facilitate rapid and successful establishment of the young polyploid in nature, increase its competition with the parental species, and improve its adaptability to new environments.

The low-copy, noncoding sequences that most of which are chromosome specific tend to cluster in several specific regions in each chromosome arm of hexaploid wheat [123]. These regions, being perhaps the only homologous-specific regions in every chromosome pair, may play an important role in processes of pairing initiation at early stages of meiosis [24]. Indeed, recent data (G. Grafi, B. Liu, F. Han, C. Melamed-Bessudo, and M. Feldman, unpublished) indicate that chromosome-specific sequences possess polycomb response elements (PREs) that bind specifically premeiotic proteins. It is speculated (G. Grafi, B. Liu, F. Han, C. Melamed-Bessudo, and M. Feldman, unpublished) that meiotic pairing is initiated by complexing the PREs of the chromosome-specific sequences with premeiotic proteins.

In addition, rapid elimination of low-copy, coding sequences may reduce the dosage of alleles from four to two when extra dose has a negative adaptive value as well as may regulate gene expression, thus leading to improved intergenomic interactions $[25,26]$. Rapid nonrandom elimination of repetitious sequences may bring about a greater harmony in the function of the different genomes of the allopolyploid [81]. Likewise, Pai et al. [71] suggested that elimination of chromosomal material from allopolyploid wheat might have been an important factor in the conversion of the allopolyploid species of wheat into functional diploids. Elimination of repetitive sequences may reduce negative nucleotypic effects of increased DNA amount as well as reducing the biochemical costs associated with this extra DNA [10].

\section{References}

[1] J. Doležel and J. Bartoš, "Plant DNA flow cytometry and estimation of nuclear genome size," Annals of Botany, vol. 95, no. 1, pp. 99-110, 2005.

[2] M. D. Bennett, P. Bhandol, and I. J. Leitch, "Nuclear DNA amounts in angiosperms and their modern uses-807 new estimates," Annals of Botany, vol. 86, no. 4, pp. 859-909, 2000.

[3] J. L. Bennetzen, J. Ma, and K. M. Devos, "Mechanisms of recent genome size variation in flowering plants," Annals of Botany, vol. 95, no. 1, pp. 127-132, 2005.

[4] M. D. Bennett and I. J. Leitch, "Nuclear DNA amounts in angiosperms," Annals of Botany, vol. 76, no. 2, pp. 113-176, 1995.

[5] I. J. Leitch, D. E. Soltis, P. S. Soltis, and M. D. Bennett, "Evolution of DNA amounts across land plants (Embryophyta)," Annals of Botany, vol. 95, no. 1, pp. 207-217, 2005.

[6] M. Frediani, N. Colonna, R. Cremonini et al., "Redundancy modulation of nuclear DNA sequences in Dasypyrum villosum," Theoretical and Applied Genetics, vol. 88, no. 2, pp. 167174, 1994.

[7] K. P. Singh, S. N. Raina, and A. K. Singh, "Variation in chromosomal DNA associated with the evolution of Arachis species," Genome, vol. 39, no. 5, pp. 890-897, 1996.

[8] R. Kalendar, J. Tanskanen, S. Immonen, E. Nevo, and A. H. Schulman, "Genome evolution of wild barley (Hordeum spontaneum) by BARE-1 retrotransposon dynamics in response to sharp microclimatic divergence," Proceedings of the National Academy of Sciences of the United States of America, vol. 97, no. 12, pp. 6603-6607, 2000.

[9] J. Greilhuber, "Intraspecific variation in genome size in angiosperms: identifying its existence," Annals of Botany, vol. 95, no. 1, pp. 91-98, 2005.

[10] I. J. Leitch and M. D. Bennett, "Genome downsizing in polyploid plants," Biological Journal of the Linnean Society, vol. 82, no. 4, pp. 651-663, 2004.

[11] S. C. Verma and H. Rees, "Nuclear DNA and evolution of allotetraploid Brassiceae," Heredity, vol. 33, no. 1, pp. 61-68, 1974.

[12] Y. Furuta, K. Nishikawa, and T. Kimizuka, "Quantitative comparison of the nuclear DNA in section sitopsis of the genus Aegilops," Japanese Journal of Genetics, vol. 50, no. 5, pp. 383-392, 1975.

[13] J. C. Pires, J. Zhao, M. E. Schranz et al., "Flowering time divergence and genomic rearrangements in resynthesized Brassica polyploids (Brassicaceae)," Biological Journal of the Linnean Society, vol. 82, no. 4, pp. 675-688, 2004.

[14] T. Garnatje, S. Garcia, R. Vilatersana, and J. Vallès, "Genome size variation in the genus Carthamus (Asteraceae, Cardueae): systematic implications and additive changes during allopolyploidization," Annals of Botany, vol. 97, no. 3, pp. 461-467, 2006.

[15] K. P. Vogel, K. Arumuganathan, and K. B. Jensen, "Nuclear DNA content of perennial grasses of the Triticeae," Crop Science, vol. 39, no. 3, pp. 661-667, 1999.

[16] S. S. Jakob, A. Meister, and F. R. Blattner, "The considerable genome size variation of hordeum species (Poaceae) is linked to phylogeny, life form, ecology, and speciation rates," Molecular Biology and Evolution, vol. 21, no. 5, pp. 860-869, 2004.

[17] H. Ozkan, M. Tuna, and D. W. Galbraith, "No DNA loss in autotetraploids of Arabidopsis thaliana," Plant Breeding, vol. 125, no. 3, pp. 288-291, 2006. 
[18] T. Eilam, Y. Anikster, E. Millet, J. Manisterski, O. Sagi-Assif, and M. Feldman, "Genome size and genome evolution in diploid Triticeae species," Genome, vol. 50, no. 11, pp. 10291037, 2007.

[19] T. Eilam, Y. Anikster, E. Millet, J. Manisterski, and M. Feldman, "Nuclear DNA amount and genome downsizing in natural and synthetic allopolyploids of the genera Aegilops and Triticum," Genome, vol. 51, no. 8, pp. 616-627, 2008.

[20] T. Eilam, Y. Anikster, E. Millet, J. Manisterski, and M. Feldman, "Genome size in natural and synthetic autopolyploids and in a natural segmental allopolyploid of several Triticeae species," Genome, vol. 52, no. 3, pp. 275-285, 2009.

[21] M. D. Bennett and I. J. Leitch, "Plant DNA C-values database (release 2.0)," October 2003, http://www.rbgkew.org.uk/ cval/homepage.html.

[22] M. D. Bennett and I. J. Leitch, "Plant DNA C-values database (release 6.0)," October 2005, http://www.rbgkew.org.uk/ cval/homepage.html.

[23] S. Sakamoto, "The cytogenetic evolution of Triticea grasses," in Chromosome Engineering in Plants: Genetics, Breeding, Evolution, Part A, P. K. Gupta and T. Tsuchiya, Eds., pp. 469481, Elsevier, Amsterdam, The Netherlands, 1987.

[24] M. Feldman, B. Liu, G. Segal, S. Abbo, A. A. Levy, and J. M. Vega, "Rapid elimination of low-copy DNA sequences in polyploid wheat: a possible mechanism for differentiation of homoeologous chromosomes," Genetics, vol. 147, no. 3, pp. 1381-1387, 1997.

[25] M. Feldman and A. A. Levy, "Allopolyploidy—a shaping force in the evolution of wheat genomes," Cytogenetic and Genome Research, vol. 109, no. 1-3, pp. 250-258, 2005.

[26] M. Feldman and A. A. Levy, "Genome evolution in allopolyploid wheat-a revolutionary reprogramming followed by gradual changes," Journal of Genetics and Genomics, vol. 36, no. 9, pp. 511-518, 2009.

[27] W. D. Clayton and S. A. Renvoize, Genera Gramineum: Grasses of the World, vol. 13 of Kew Bulletin Additional Series, Royal Botanical Gardens, Kew, UK, 1986.

[28] A. Eig, "Monographisch-kritische Übersicht der Gattung Aegilops," Feddes Repertorium Specierum Novarum Regni Vegetabilis Beih, vol. 55, pp. 1-228, 1929.

[29] M. W. Van Slageren, "Wild wheats: a monograph of Aegilops L. and Amblyopyrum (Jaub. \& Spach) Eig (Poaceae)," Wageningen Agricultural University Papers, vol. 94-7, pp. 1-512, 1994.

[30] R. R.-C. Wang, R. von Bothmer, J. Dvorak, et al., "Genome designation in the Triticeae. (Poaceae)," in Proceedings of the 2nd International Triticeae Symposium, R. R.-C. Wang, Ed., pp. 29-34, Utah State University Press, 1996.

[31] G. Kimber and K. Tsunewaki, "Genome symbols and plasma types in the wheat group," in Proceedings of the 7th International Wheat Genetics Symposium, T. E. Miller and R. M. D. Koebner, Eds., vol. 2, pp. 1209-1211, Cambridge, UK, 1988.

[32] M. Baranyi and J. Greilhuber, "Flow cytometric analysis of genome size variation in cultivated and wild Pisum sativum (Fabaceae)," Plant Systematics and Evolution, vol. 194, no. 34, pp. 231-239, 1995.

[33] M. Baranyi and J. Greilhuber, "Flow cytometric and Feulgen densitometric analysis of genome size variation in Pisum," Theoretical and Applied Genetics, vol. 92, no. 3-4, pp. 297307, 1996.

[34] M. Baranyi, J. Greilhuber, and W. K. Swiecicki, "Genome size in wild Pisum species," Theoretical and Applied Genetics, vol. 93, no. 5-6, pp. 717-721, 1996.
[35] J. Greilhuber and R. Obermayer, "Genome size and maturity group in Glycine max (soybean)," Heredity, vol. 78, no. 5, pp. 547-551, 1997.

[36] M. Le Thierry D’Ennequin, O. Panaud, S. Brown, S. SiljakYakovlev, and A. Sarr, "First evaluation of nuclear DNA content in Setaria genus by flow cytometry," Journal of Heredity, vol. 89, no. 6, pp. 556-559, 1998.

[37] R. Obermayer and J. Greilhuber, "Genome size in Chinese soybean accessions-stable or variable?" Annals of Botany, vol. 84, no. 2, pp. 259-262, 1999.

[38] M. D. Bennett, S. Johnston, G. L. Hodnett, and H. J. Price, "Allium cepa L. cultivars from four continents compared by flow cytometry show nuclear DNA constancy," Annals of Botany, vol. 85, no. 3, pp. 351-357, 2000.

[39] M. A. Lysák, A. Rostková, J. M. Dixon, G. Rossi, and J. Doležel, "Limited genome size variation in Sesleria albicans," Annals of Botany, vol. 86, no. 2, pp. 399-403, 2000.

[40] P. Ellul, M. Boscaiu, O. Vicente, V. Moreno, and J. A. Rosselló, "Intra- and interspecific variation in DNA content in Cistus (Cistaceae)," Annals of Botany, vol. 90, no. 3, pp. 345-351, 2002.

[41] E. A. Moscone, M. Baranyi, I. Ebert, J. Greilhuber, F. Ehrendorfer, and A. T. Hunziker, "Analysis of nuclear DNA content in Capsicum (Solanaceae) by flow cytometry and feulgen densitometry," Annals of Botany, vol. 92, no. 1, pp. 21-29, 2003.

[42] J. Greilhuber, "Intraspecific variation in genome size: a critical reassessment," Annals of Botany, vol. 82, supplement A, pp. 27-35, 1998.

[43] B. G. Murray, "When does intraspecific C-value variation become taxonomically significant?" Annals of Botany, vol. 95, no. 1, pp. 119-125, 2005.

[44] D. C. Albach and J. Greilhuber, "Genome size variation and evolution in Veronica," Annals of Botany, vol. 94, no. 6, pp. 897-911, 2004.

[45] H. Rees and M. H. Hazarika, "Chromosome evolution in Lathyrus," in Chromosome Today, C. D. Darlington and K. R. Lewis, Eds., pp. 158-165, Oliver and Boyd, Edinburgh, UK, 1969.

[46] M. D. Bennett, "Nuclear DNA content and minimum generation time in herbaceous plants," Proceedings of the Royal Society of London B, vol. 181, no. 63, pp. 109-135, 1972.

[47] F. Sabot, R. Guyot, T. Wicker et al., "Updating of transposable element annotations from large wheat genomic sequences reveals diverse activities and gene associations," Molecular Genetics and Genomics, vol. 274, no. 2, pp. 119-130, 2005.

[48] A. Kumar and J. L. Bennetzen, "Plant retrotransposons," Annual Review of Genetics, vol. 33, pp. 479-532, 1999.

[49] C. M. Vicient, M. J. Jääskeläinen, R. Kalendar, and A. H. Schulman, "Active retrotransposons are a common feature of grass genomes," Plant Physiology, vol. 125, no. 3, pp. 12831292, 2001.

[50] G. Caetano-Anollés, "Evolution of genome size in the grasses," Crop Science, vol. 45, no. 5, pp. 1809-1816, 2005.

[51] J. L. Bennetzen and E. A. Kellogg, "Do plants have a one-way ticket to genome obesity?" The Plant Cell, vol. 9, no. 9, pp. 1509-1514, 1997.

[52] J. L. Bennetzen, "Transposable element contributions to plant gene and genome evolution," Plant Molecular Biology, vol. 42, no. 1, pp. 251-269, 2000.

[53] J. L. Bennetzen, "Mechanisms and rates of genome expansion and contraction in flowering plants," Genetica, vol. 115, no. 1, pp. 29-36, 2002. 
[54] J. F. Wendel, R. C. Cronn, J. S. Johnston, and H. J. Price, "Feast and famine in plant genomes," Genetica, vol. 115, no. 1, pp. 37-47, 2002.

[55] C. M. Vicient, A. Suoniemi, K. Anamthawat-Jonsson et al., "Retrotransposon BARE-1 and its role in genome evolution in the genus Hordeum," Plant Cell, vol. 11, no. 9, pp. 17691784, 1999.

[56] K. Shirasu, A. H. Schulman, T. Lahaye, and P. Schulze-Lefert, "A contiguous 66-kb barley DNA sequence provides evidence for reversible genome expansion," Genome Research, vol. 10, no. 7, pp. 908-915, 2000.

[57] K. M. Devos, J. K. M. Brown, and J. L. Bennetzen, "Genome size reduction through illegitimate recombination counteracts genome expansion in Arabidopsis," Genome Research, vol. 12, no. 7, pp. 1075-1079, 2002.

[58] J. L. Bennetzen, C. Coleman, R. Liu, J. Ma, and W. Ramakrishna, "Consistent over-estimation of gene number in complex plant genomes," Current Opinion in Plant Biology, vol. 7, no. 6, pp. 732-736, 2004.

[59] N. Fedoroff, "Transposons and genome evolution in plants," Proceedings of the National Academy of Sciences of the United States of America, vol. 97, no. 13, pp. 7002-7007, 2000.

[60] E. Paux, D. Roger, E. Badaeva et al., "Characterizing the composition and evolution of homoeologous genomes in hexaploid wheat through BAC-end sequencing on chromosome 3B," Plant Journal, vol. 48, no. 3, pp. 463-474, 2006.

[61] V. Walbot and C. A. Cullis, "Rapid genomic change in higher plants," Annual Review of Plant Physiology, vol. 36, pp. 367396, 1985.

[62] M.-A. Grandbastien, "Activation of plant retrotransposons under stress conditions," Trends in Plant Science, vol. 3, no. 5, pp. 181-187, 1998.

[63] B. McClintock, "The significance of responses of the genome to challenge," Science, vol. 226, no. 4676, pp. 792-801, 1984.

[64] M. Feldman, F. G. H. Lupton, and T. E. Miller, "Wheats," in Evolution of Crop Plants, J. Smartt and N.W. Simmonds, Eds., pp. 184-192, Longman Scientific, London, UK, 2nd edition, 1995.

[65] H. Ozkan, A. A. Levy, and M. Feldman, "Allopolyploidyinduced rapid genome evolution in the wheat (AegilopsTriticum) group," Plant Cell, vol. 13, no. 8, pp. 1735-1747, 2001.

[66] H. Rees, "Deoxyribonucleic acid and the ancestry of wheat," Nature, vol. 198, no. 4875, pp. 108-109, 1963.

[67] H. Rees and M. R. Walters, "Nuclear DNA and the evolution of wheat," Heredity, vol. 20, no. 1, pp. 73-82, 1965.

[68] K. Nishikawa and Y. Furuta, "DNA content per nucleus in relation to phylogeny of wheat and its relatives," The Japanese Journal of Genetics, vol. 44, no. 1, pp. 23-29, 1969.

[69] C. Pegington and H. Rees, "Chromosome weights and measures in the Triticinae," Heredity, vol. 25, no. 2, pp. 195205, 1970.

[70] Y. Furuta, K. Nishikawa, and T. Tanino, "Stability in DNA content of $\mathrm{AB}$ genome component of common wheat during the past seven thousand years," The Japanese Journal of Genetics, vol. 49, no. 4, pp. 179-187, 1974.

[71] R. A. Pai, M. D. Upadhya, S. Bhaskaran, and M. S. Swaminathan, "Chromosome diminution and evolution of polyploid species in triticum," Chromosoma, vol. 12, no. 1, pp. 398-409, 1961.

[72] M. D. Upadhya and M. S. Swaminathan, "Deoxyribonucleic acid and the ancestry of wheat," Nature, vol. 200, no. 4907, pp. 713-714, 1963.
[73] E. V. Boyko, N. S. Badaev, N. G. Maximov, and A. V. Zelenin, "Does DNA content change in the course of Triticale breeding?" Cereal Research Communication, vol. 12, pp. 99$100,1984$.

[74] E. V. Boyko, N. S. Badaev, N. G. Maximov, and A. V. Zelenin, "Regularities of genome formation and organization in cereals. I. DNA quantitative changes in the process of allopolyploidization," Genetika, vol. 24, pp. 89-97, 1988.

[75] B. Liu, J. M. Vega, G. Segal, S. Abbo, M. Rodova, and M. Feldman, "Rapid genomic changes in newly synthesized amphiploids of Triticum and Aegilops. I. Changes in low-copy noncoding DNA sequences," Genome, vol. 41, no. 2, pp. 272277, 1998.

[76] B. Liu, J. M. Vega, and M. Feldman, "Rapid genomic changes in newly synthesized amphiploids of Triticum and Aegilops. II. Changes in low-copy coding DNA sequences," Genome, vol. 41, no. 4, pp. 535-542, 1998.

[77] H. Ozkan, A. A. Levy, and M. Feldman, "Rapid differentiation of homeologous chromosomes in newly-formed allopolyploid wheat," Israel Journal of Plant Sciences, vol. 50, pp. S65-S76, 2002.

[78] H. Shaked, K. Kashkush, H. Ozkan, M. Feldman, and A. A. Levy, "Sequence elimination and cytosine methylation are rapid and reproducible responses of the genome to wide hybridization and allopolyploidy in wheat," Plant Cell, vol. 13, no. 8, pp. 1749-1759, 2001.

[79] E. A. Salina, O. M. Numerova, H. Ozkan, and M. Feldman, "Alterations in subtelomeric tandem repeats during early stages of allopolyploidy in wheat," Genome, vol. 47, no. 5, pp. 860-867, 2004.

[80] F. P. Han, G. Fedak, T. Ouellet, and B. Liu, "Rapid genomic changes in interspecific and intergeneric hybrids and allopolyploids of Triticeae," Genome, vol. 46, no. 4, pp. 716723, 2003.

[81] F. Han, G. Fedak, W. Guo, and B. Liu, "Rapid and repeatable elimination of a parental genome-specific repeat (pGc1R1a) in newly synthesized wheat allopolyploids," Genetics, vol. 170, no. 3, pp. 1239-1245, 2005.

[82] X.-F. Ma and J. P. Gustafson, "Genome evolution of allopolyploids: a process of cytological and genetic diploidization," Cytogenetic and Genome Research, vol. 109, no. 1-3, pp. 236249, 2005.

[83] X.-F. Ma and J. P. Gustafson, "Timing and rate of genome variation in triticale following allopolyploidization," Genome, vol. 49, no. 8, pp. 950-958, 2006.

[84] X.-F. Ma, P. Fang, and J. P. Gustafson, "Polyploidizationinduced genome variation in triticale," Genome, vol. 47, no. 5, pp. 839-848, 2004.

[85] Y. Furuta, K. Nishikawa, T. Makino, and Y. Sawai, "Variation in DNA content of 21 individual chromosomes among six subspecies in common wheat," Japanese Journal of Genetics, vol. 59, no. 1, pp. 83-90, 1984.

[86] H. Ozkan, M. Tuna, and K. Arumuganathan, "Nonadditive changes in genome size during allopolyploidization in the wheat (Aegilops-Triticum) group," Journal of Heredity, vol. 94, no. 3, pp. 260-264, 2003.

[87] E. R. Kerber, "Wheat: reconstitution of the tetraploid component (AABB) of hexaploids," Science, vol. 143, no. 3603, pp. 253-255, 1964.

[88] P. J. Kaltsikes, L. E. Evans, and E. N. Larter, "Morphological and meiotic characteristics of the extracted AABB tetraploid component of three varieties of common wheat," Canadian Journal of Genetics and Cytology, vol. 11, no. 1, pp. 65-71, 1969. 
[89] K. Nishikawa and Y. Furuta, "DNA content of nucleus and individual chromosomes and its evolutionary significance," in Proceedings of the 5th International Wheat Genetics Symposium, E. Ramanujan, Ed., vol. 1, pp. 133-138, Indian Society of Genetics \& Plant Breeding, 1978.

[90] K. Nishikawa, Y. Furuta, S. Kudo, and K. Ujihara, "Differentiation of tetraploid wheat in relation to DNA content of nucleus and alpha-amylase isozymes," Report from the Plant Germplasm Institute, vol. 4, pp. 30-38, 1979.

[91] M. Vaio, C. Mazzella, V. Porro et al., "Nuclear DNA content in allopolyploid species and synthetic hybrids in the grass genus Paspalum," Plant Systematics and Evolution, vol. 265, no. 1-2, pp. 109-121, 2007.

[92] J. S. Johnston, A. E. Pepper, A. E. Hall et al., "Evolution of genome size in Brassicaceae," Annals of Botany, vol. 95, no. 1, pp. 229-235, 2005.

[93] J. W. Morrison and T. Rajhathy, "Chromosome behaviour in autotetraploid cereals and grasses," Chromosoma, vol. 11, no. 1, pp. 297-309, 1960.

[94] J. W. Morrison and T. Rajhathy, "Frequency of quadrivalents in autotetraploid plants," Nature, vol. 187, no. 4736, pp. 528530, 1960.

[95] R. B. Jørgensen, "Biosystematics of Hordeum bulbosum L.," Nordic Journal of Botany, vol. 2, no. 5, pp. 421-434, 1982.

[96] W. K. Heneen and H. Runemark, "Cytology of the Elymus (Agropyron) elongatus complex," Hereditas, vol. 70, no. 2, pp. 155-164, 1972.

[97] A. Charpentier, M. Feldman, and Y. Cauderon, "Genetic control of meiotic chromosome pairing in tetraploid Agropyron elongatum. I. Pattern of pairing in natural and induced tetraploids and in $\mathrm{F}_{1}$ triploid hybrid," Canadian Journal of Genetics and Cytology, vol. 28, no. 5, pp. 783-788, 1986.

[98] A. Charpentier, Y. Cauderon, and M. Feldman, "Control of chromosome pairing in Agropyron elongatum," in Proceedings of the 7th International Wheat Genetics Symposium, T. E. Miller and R. M. D. Koebner, Eds., pp. 231-236, Cambridge, UK, 1988.

[99] P. K. Gupta and G. Fedak, "Genetic control of meiotic chromosome pairing in polyploids in the genus Hordeum," Canadian Journal of Genetics and Cytology, vol. 27, no. 5, pp. 515-530, 1985.

[100] R. von Bothmer, N. Jacobsen, C. Baden, R. B. Jørgensen, and I. Linde-Larrsen, "An ecogeographical study of the genus Hordeum," in Systematic and Ecogeographic Studies on Crop Genepools. 7. International Plant Genetic, Resources Institute, Rome, Italy, 2nd edition, 1995.

[101] F. R. Blattner, "Phylogenetic analysis of Hordeum (Poaceae) as inferred by nuclear rDNA ITS sequences," Molecular Phylogenetics and Evolution, vol. 33, no. 2, pp. 289-299, 2004.

[102] P. Šmarda, P. Bureš, L. Horová, B. Foggi, and G. Rossi, "Genome size and GC content evolution of Festuca: ancestral expansion and subsequent reduction," Annals of Botany, vol. 101, no. 3, pp. 421-433, 2008.

[103] D. Ohri, R. M. Fritsch, and P. Hanelt, "Evolution of genome size in allium (alliaceae)," Plant Systematics and Evolution, vol. 210, no. 1-2, pp. 57-86, 1998.

[104] Y. Yamaguchi and S. Tsunoda, "Nuclear volume, nuclear DNA content and radiosensitivity in Brassica and allied genera," Japanese Journal of Plant Breeding, vol. 19, no. 5, pp. 350-356, 1969.

[105] A. G. Seal, "DNA variation in Festuca," Heredity, vol. 50, no. 3, pp. 225-236, 1983.
[106] S. N. Raina, A. Parida, K. K. Koul et al., "Associated chromosomal DNA changes in polyploids," Genome, vol. 37 , no. 4, pp. 560-564, 1994.

[107] T. Rajhathy and J. W. Morrison, "Cytogenetic studies in the genus Hordeum. IV. The murinum complex," Canadian Journal of Genetics and Cytology, vol. 4, no. 2, pp. 240-247, 1962.

[108] R. von Bothmer, J. Flink, N. Jacobsen, and R. B. Jørgensen, "Variation and differentiation in Hordeum marinum (Poaceae)," Nordic Journal of Botany, vol. 9, no. 1, pp. 1-10, 1989.

[109] J. Dvorak, "Genome relationships among Elytrigia (=Agropyron) elongata. E. stipifolia, "E. elongata $4 x$ ”, E. caespitosa, E. intermedia, and "E. elongata 10x",' Genome, vol. 23, no. 3, pp. 481-492, 1981.

[110] R. von Bothmer, J. Flink, and T. Landström, "Meiosis in interspecific Hordeum hybrids. IV. Tetraploids (4x x 4x) hybrids," Genome, vol. 30, no. 4, pp. 479-485, 1988.

[111] N. Jacobsen and R. von Bothmer, "Supraspecific groups in the genus Hordeum," Hereditas, vol. 116, no. 1-2, pp. 21-24, 1992.

[112] I. B. Linde-Laursen, R. von Bothmer, and N. Jacobsen, "Relationships in the genus Hordeum: giemsa C-banded karyotypes," Hereditas, vol. 116, no. 1-2, pp. 111-116, 1992.

[113] A. De Bustos, A. Cuadrado, C. Soler, and N. Jouve, "Physical mapping of repetitive DNA sequences and 5S and 18S$26 \mathrm{~S}$ rDNA in five wild species of the genus Hordeum," Chromosome Research, vol. 4, no. 7, pp. 491-499, 1996.

[114] R. B. Jørgensen, "Relationships in the barley genus (Hordeum): an electrophoretic examination of proteins," Hereditas, vol. 104, no. 2, pp. 273-291, 1986.

[115] V. Jaaska, "Isoenzyme variation in barley (Hordeum L.) 2. Aspartate aminotransferase and 6-phosphoglyconate dehydrogenase," Hereditas, vol. 116, no. 1-2, pp. 29-35, 1992.

[116] T. Nishikawa, B. Salomon, and H. Nordenskiöld, "A genetical study in the mode of segregation in hexaploid Phleum pratense," Hereditas, vol. 39, pp. 369-488, 1953.

[117] H. Nordenskiöld, "Segregation ratios in progenies of hybrids between natural and synthesized Phleum pratense," Hereditas, vol. 43, pp. 525-540, 1957.

[118] C. D. R. Dawson, "Tetrasomic inheritance in Lotus corniculatus L.," Journal of Genetics, vol. 42, pp. 49-72, 1941.

[119] V. Jaaska, "Isoenzyme evidence on the systematics of Hordeum spp. section Marina (Poaceae)," Plant Systematics and Evolution, vol. 191, no. 3-4, pp. 213-226, 1994.

[120] A. A. Levy and M. Feldman, "The impact of polyploidy on grass genome evolution," Plant Physiology, vol. 130, no. 4, pp. 1587-1593, 2002.

[121] A. A. Levy and M. Feldman, "Genetic and epigenetic reprogramming of the wheat genome upon allopolyploidization," Biological Journal of the Linnean Society, vol. 82, no. 4, pp. 607-613, 2004.

[122] H. Ozkan and M. Feldman, "Rapid cytological diploidization in newly formed allopolyploids of the wheat (AegilopsTriticum) group," Genome, vol. 52, no. 11, pp. 926-934, 2009.

[123] B. Liu, G. Segal, J. M. Vega, M. Feldman, and S. Abbo, "Isolation and characterization of chromosome-specific DNA sequences from a chromosome arm genomic library of common wheat," Plant Journal, vol. 11, no. 5, pp. 959-965, 1997. 

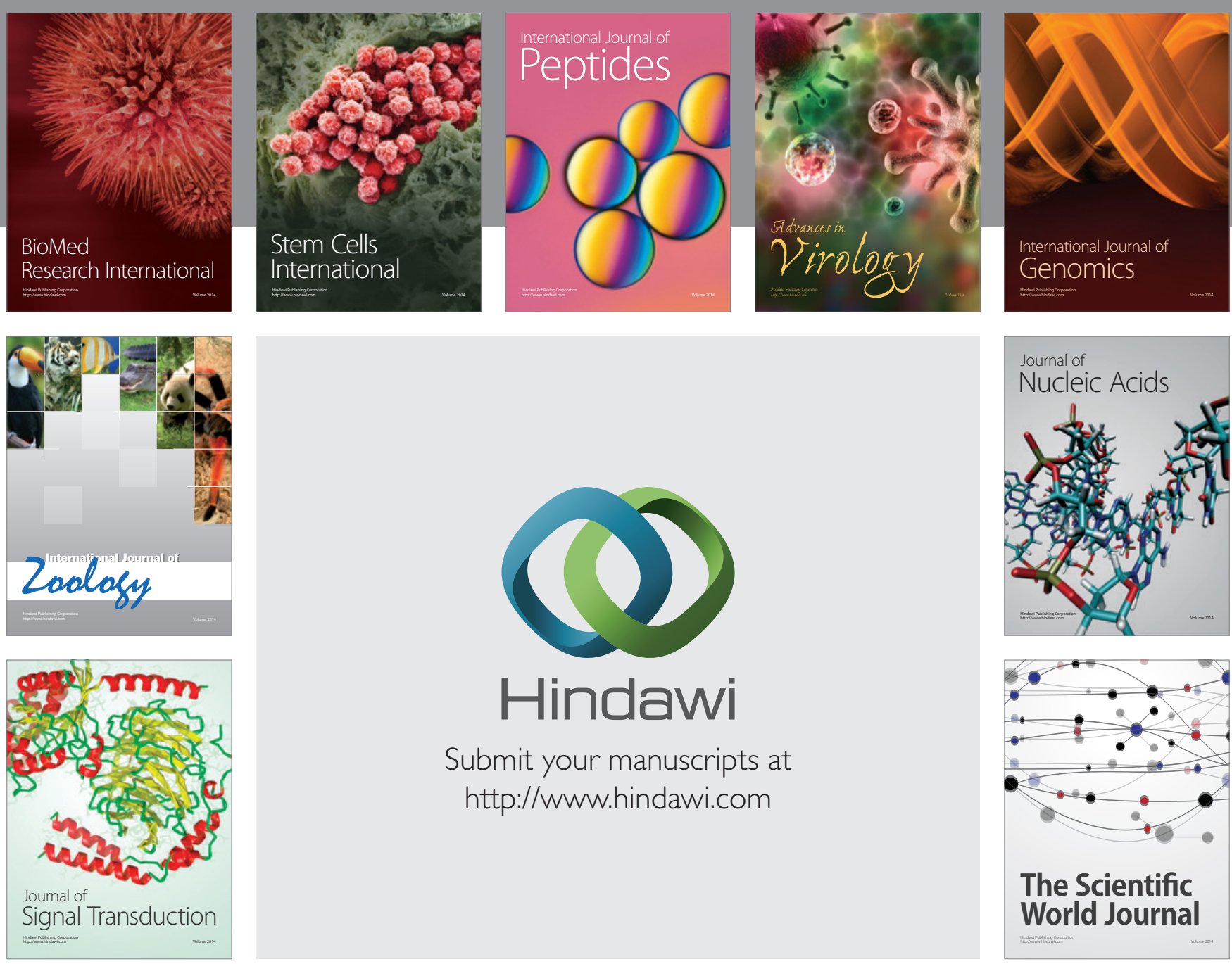

Submit your manuscripts at

http://www.hindawi.com
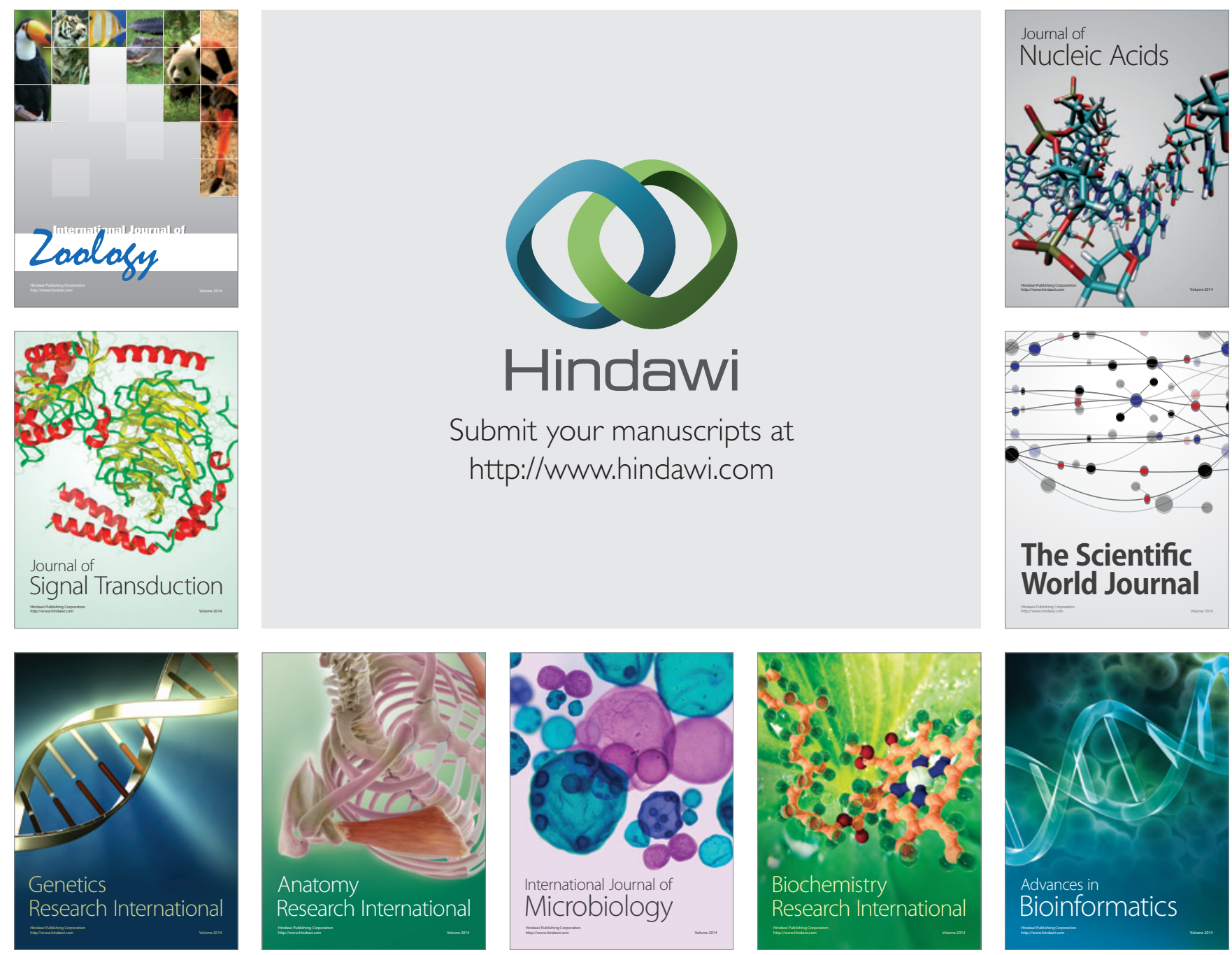

The Scientific World Journal
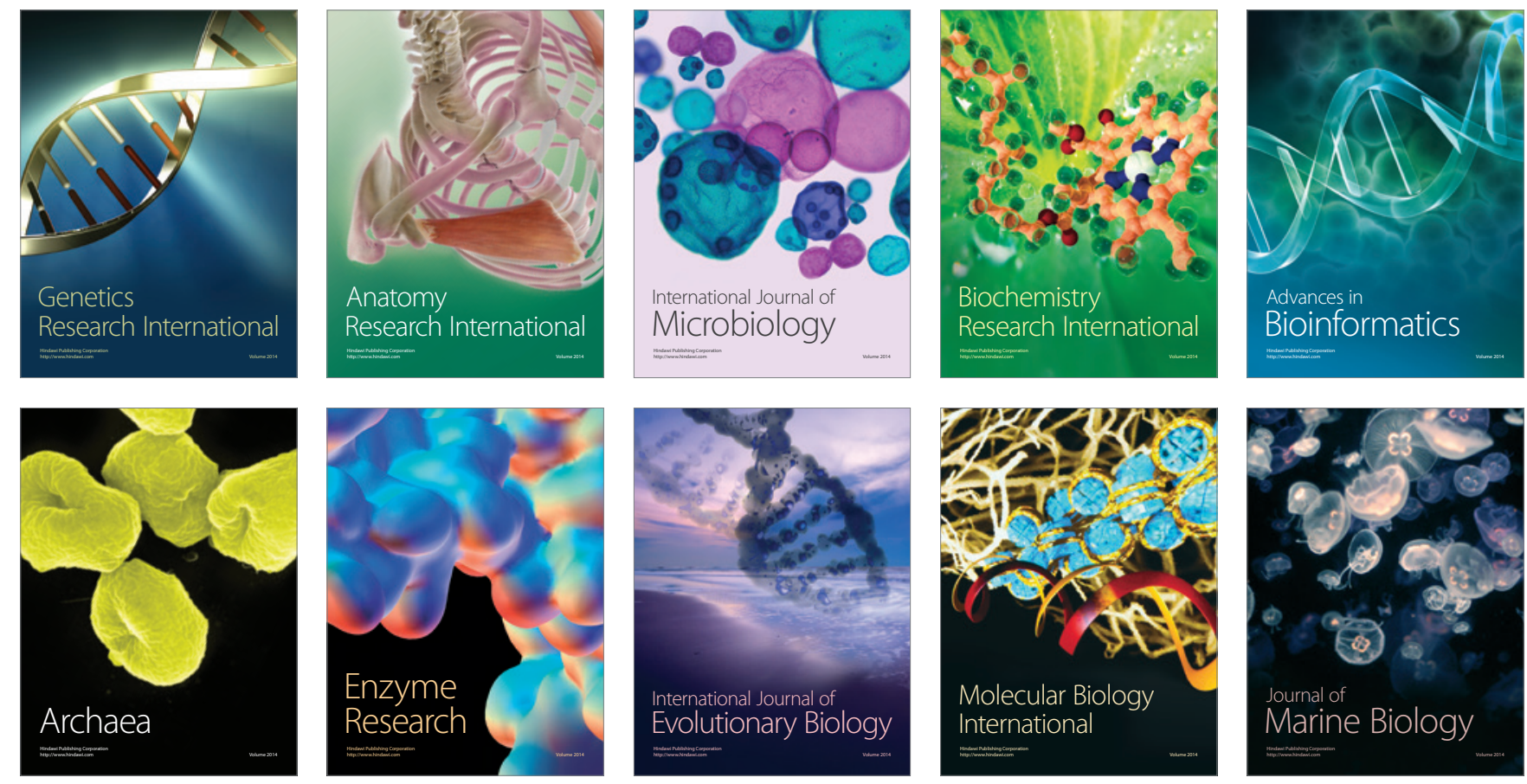